Farum

Sociológico

\section{Forum Sociológico}

Série II

$19 \mid 2009$

As Forças Armadas numa sociedade em mudança

\title{
Mercado de arte contemporânea: construção do valor artístico e do estatuto de mercado do artista
}

Filipa Almeida

\section{(2) OpenEdition \\ 12 Journals}

Edição electrónica

URL: https://journals.openedition.org/sociologico/203

DOI: 10.4000/sociologico.203

ISSN: 2182-7427

Editora

CICS.NOVA - Centro Interdisciplinar de Ciências Sociais da Universidade Nova de Lisboa

\section{Edição impressa}

Data de publição: 1 junho 2009

Paginação: 63-71

ISSN: 0872-8380

\section{Refêrencia eletrónica}

Filipa Almeida, «Mercado de arte contemporânea: construção do valor artístico e do estatuto de mercado do artista», Forum Sociológico [Online], 19 | 2009, posto online no dia 20 julho 2012 consultado o 29 março 2022. URL: http://journals.openedition.org/sociologico/203 ; DOI: https:// doi.org/10.4000/sociologico.203

Este documento foi criado de forma automática no dia 29 março 2022

(c) CICS.NOVA 


\title{
Mercado de arte contemporânea: construção do valor artístico e do estatuto de mercado do artista
}

\author{
Filipa Almeida
}

\section{Valor de mercado como construção social}

1 Qualquer valor de mercado resulta de uma construção social. Por maioria de razão, esse é o caso do valor de uma obra de arte: uma vez que a percepção de qualidade do objecto, enquanto determinante do seu valor de uso, não é imediatamente objectivável através de critérios específicos, é necessário que um conjunto de actores sociais certifiquem e atribuam valor à obra.

O mercado onde se transaccionam este tipo de objectos pode ser assim analisado como um fenómeno económico, embutido numa estrutura de relações sociais que tanto podem ser tornadas maleáveis pelas forças da estrutura social e da acção colectiva, como ficar bloqueadas por essas forças (Granovetter, 2003 [1985]: 69-102). As relações sociais influenciam a forma como o produtor ou o autor de uma obra é visto, a incrustação da acção nas relações sociais ajuda ao contacto entre os produtores de arte e os consumidores, permitindo formar-se uma imagem/opinião acerca do objecto artístico, baseada não tanto nas propriedades intrínsecas do objecto como na posição ocupada pelo produtor nesse conjunto de relações (Podolny, 1993).

3 A escolha da arte contemporânea está nesta investigação relacionada com o facto de se considerar um dos mercados onde o valor é mais difícil de determinar, exactamente devido à natureza dos valores em jogo. Uma obra de arte contemporânea pode assumir os mais variados valores monetários e simbólicos. No trabalho exploratório, as questões essenciais reportam-se à forma como é conferido valor a uma obra de arte, quais os mecanismos que lhe conferem um lugar no mercado, que actores ou agentes estão envolvidos neste processo e como é que participam na construção desse valor. 
4 A análise sociológica do campo artístico é assim indispensável à sua compreensão, uma vez que só através da identificação das várias categorias de actores envolvidos, das posições por estes ocupadas e dos valores orientadores das suas acções neste processo será possível apreender que atributos são necessários para que uma obra ou um artista adquiram estatuto de mercado e lhes seja atribuído um determinado valor, e por que processos esses atributos são constituídos.

\section{Algumas contribuições teóricas}

5 A teoria de Pierre Bourdieu (1989) sobre os campos sociais, aplicada ao funcionamento e autonomia do campo artístico, serve para explicar a forma como as posições dos actores dentro deste campo poderão estruturar as suas práticas, e ainda como estas posições poderão ser hierarquizadas mediante o volume de capitais adquiridos. A teoria da dominação de Pierre Bourdieu transporta para esta investigação a necessidade de legitimação de uma obra por determinados valores ou cânones dominantes. Podendo ser a inovação radical uma das características da arte contemporânea, esta só poderá ser legítima se estiver de acordo com o discurso dominante, ou se for produzido um novo discurso de legitimação pelos actores que estão nas posições dominantes.

Decorrendo desta necessidade de legitimação e através de uma perspectiva interaccionista de Howard Becker (1982) acerca do mundo da arte contemporânea, apresenta-se a noção de convenção em torno do valor artístico. A construção de reputação artística e a aquisição de um determinado estatuto num mercado de valores estão directamente relacionadas com a construção social deste valor, ou seja, com a legitimação no campo artístico e com a coordenação necessária para que se dê essa legitimação. A articulação e cooperação entre os actores é necessária para conferir um determinado valor a uma obra de arte. De acordo com Howard Becker (ibidem), são várias as categorias de actores que participam nesta actividade coordenada. 0 galerista ou o marchand são negociantes que necessitam de um espaço no qual expõem obras de arte a potenciais compradores. Precisam também de um grupo de artistas que produzem o trabalho para ser vendido. Os compradores são essenciais para que se possam sustentar as galerias e as suas despesas inerentes. Os críticos irão produzir o discurso público indispensável para que se possa avaliar o trabalho artístico, posicionálo no mercado e construir interesse nesse trabalho. Os visitantes das galerias, mesmo que não sejam compradores, têm um papel preponderante na difusão de interesse pela galeria e pelos trabalhos aí expostos, podendo recomendá-los a outros actores.

Neste mundo artístico são estes os actores com um papel preponderante na construção de valor. Quais as práticas que estes actores utilizam na atribuição de valor? Como se efectua a coordenação dos actos e dos juízos sobre o valor dos artistas e das suas obras?

8 A contestação da noção de campo de Bourdieu pela interpretação compreensiva dos valores e ordens de grandeza convocados pelos actores foi iniciada por Luc Boltanski e Laurent Thévenot (1991). Estes autores propõem uma nova abordagem à sociologia moral e da acção, e à sociologia económica em particular, em torno da denominada "economia das convenções", privilegiando a compreensão dos processos de interpretação dos próprios actores e rompendo com a construção de Bourdieu de predisposições inscritas no habitus de cada actor. 
Optou-se, assim, por uma abordagem sociológica compreensiva, apoiada na teoria das economias de grandeza de Luc Boltanski e Laurent Thévenot (ibidem) e, mais concretamente aplicável ao mundo da arte, apresenta-se o regime de singularidade segundo Nathalie Heinich (1998a). A questão-chave para estes autores é a de quais os regimes e ordens de grandeza invocados pelos actores nas suas operações críticas e de valorização, que são mobilizados para resolver controvérsias e elaborar convenções sociais, mais ou menos precárias, mais ou menos consensuais, em torno das quais se torna possível coordenar as acções.

10 Através do conceito de cités, ou regimes de justificação das acções dos actores, descrevem-se tipos-ideais de ordens legítimas que se diferenciam por uma "metafísica política" específica organizada em torno de um princípio superior comum. Estas cités são constituídas por um princípio de ordem, que aparece como a génese da ordem de um mundo já existente e confere uma certa coerência e ordem de grandeza a este mundo (Boltanski e Thévenot, 1991).

11 Estes autores identificam seis cités, das quais, numa primeira análise, se podem hipoteticamente reconhecer quatro como predominantes no mundo da arte contemporânea:

12 Tomemos em primeiro lugar a cité da inspiração. Formulada por Sto. Agostinho na obra A Cidade de Deus, a grandeza da inspiração é designada pelo princípio da graça e da humildade. É em nome deste princípio da graça que, numa organização de cité da inspiração, as pessoas são levadas a elevarem-se acima da ordem mundana e a fazerem inovações radicais. Este mundo da inspiração privilegia a singularidade, a originalidade, a espontaneidade, sendo esta última autêntica, sincera e involuntária. Manifesta-se pelas emoções e pelas paixões e é veiculado como enriquecedor, entusiasta, exaltante, fascinante e inquietante. Este regime de justificação classifica-se de irracional, escapando à razão, à determinação e à certeza da técnica. É valorizado o que é misterioso, imaginativo, original e indizível. A paixão é o que orienta os actores neste mundo, e o desejo de criar é a inspiração revelada nos objectos. A inquietude, a dúvida e o sofrimento são grandezas perseguidas neste regime. É plausível que encontremos no mundo artístico, que normalmente justifica a acção convocando valores como a criatividade, a originalidade, a singularidade e a autenticidade, que se manifesta pelas emoções e frequentemente se qualifica de irracional, discursos de justificação muito próximos do regime de inspiração. Assim, este regime está na génese do regime de singularidade, apresentado por Nathalie Heinich para caracterizar o regime de valores actualmente existente no mundo da arte contemporânea, referido mais à frente neste artigo. Pode mesmo considerar-se que o regime de singularidade é um subtipo da cité da inspiração, especificado para a época contemporânea do mundo das artes.

13 No entanto, o problema da valorização social da obra de arte complexifica-se porque o regime da inspiração não coincide com outros regimes igualmente presentes no mundo da arte contemporânea. Alguns dos actores envolvidos neste mundo terão as suas acções justificadas pelo regime mercantil, ao passo que a coordenação e a formação de equivalências entre este e o regime de inspiração obrigará provavelmente, como decorre do acima referido sobre a importância da reputação no estabelecimento do valor mercantil da singularidade, à convocação do regime de opinião.

14 Na cité mercantil, os princípios convocados são o funcionamento do mercado e o interesse egoísta do lucro. Estes princípios, cuja origem está no funcionamento dos mercados concebido por Adam Smith, estão relacionados com a concorrência pela 
posse exclusiva dos mesmos bens raros por muitas pessoas. A cité mercantil coloca ênfase na qualidade dos objectos transaccionados e no papel da coordenação necessária para que as transacções se realizem. A racionalidade, a distância emocional e o controlo das emoções são condições necessárias para detectar as oportunidades do mercado e fazer bons negócios sem ser dominado por sentimentos impulsivos.

Expressões como "a arte não tem preço" ou a "arte pela arte" remetem para um discurso anti-mercantil muitas vezes enunciado pelos artistas e pelos próprios galeristas. A associação ao valor monetário e ao negócio não faz parte dos valores que legitimam a acção no mundo da inspiração artística, por mais que a racionalidade económica seja um imperativo para a actuação dos actores no mercado da arte. Assim, podemos conjecturar que a prática mercantil de negociar as obras de arte terá de ser justificada através de outros valores de maior grandeza, que permitam eclipsar estes valores não legítimos. A ser assim, de acordo com esta perspectiva teórica, a prática comercial dos galeristas terá de ser justificada como um instrumento ao serviço de valores de grandeza maior no mundo da arte, como os do regime de inspiração ou mesmo os valores de um regime de projecto, cuja emergência constitui a hipótese de Boltanski e Chiapello (1999), em que as redes e a colaboração entre os vários actores seriam legitimadas com a ideia da concretização de um projecto artístico comum, ao serviço do qual as práticas mercantis seriam meramente instrumentais. Quais são então os discursos dos galeristas para legitimar a sua acção mercantil e de sustentação económica, e dos artistas para justificar a sua relação com o mercado?

Das considerações tecidas acima acerca da importância das relações sociais entre actores com posições hierárquicas diferenciadas, também poderá ser identificado no mundo artístico o regime da cité doméstica. A grandeza doméstica é descrita como aquela em que as pessoas se encontram ligadas por uma corrente de dependência pessoal dentro de uma hierarquia de posições, tal como a pertença a uma família, a uma linhagem ou, no caso do mundo da arte, a uma "linhagem de influência", a uma escola ou a uma clique, e em que orientam as suas acções com base na fidelidade a princípios tradicionais e a uma figura que se respeita e a quem se deve lealdade. Mas, na medida em que estas grandezas ocorram, não aparecerão justificadas, também elas, na linguagem da cité de projecto, invocando os princípios de colaboração e aprendizagem em rede mobilizados para a realização de projectos inovadores, hipoteticamente mais compatível com a liberdade artística do regime de inspiração do que a estrita dependência hierárquica do regime doméstico, ou da percepção de notoriedade e atribuição de reputação do regime de opinião?

17 A cité de renome ou cité de opinião é aquela que permite, através de uma concepção hobbesiana de honra, a construção desta hierarquia de posições baseada na construção de reputações. A grandeza deste regime justificativo depende exclusivamente da opinião dos outros, isto é, do número e da qualidade das pessoas que concedem um valor que exclusivamente assente na notoriedade e no renome. Aplicando ao mundo artístico, a grandeza do regime de opinião será assente na atribuição de valor apoiada em percepções de estatuto e de reputação, originando uma hierarquia de notoriedade.

18 A cada uma das cités corresponde um mundo de qualificações, no qual os actores se apoiam para se qualificarem e se atribuírem diferentes estados de grandeza. Deste modo, se a ordem de uma cité legitima uma forma de estar no mundo através de um princípio superior, comum a todos os que se justificam com esse princípio, supõe-se que, reciprocamente, os actores, para se qualificarem, deverão justificar-se sempre 
apoiando-se na coerência dos dispositivos que constituem o mundo que lhes é comum (Lévesque et al., 2001).

Mais interessante, para este caso, é a questão da coexistência no mesmo mundo de diferentes ordens de grandeza, das suas tensões mas também da forma como a construção de mediações e de princípios de equivalência permite a coordenação entre os actores regidos por ordens de grandeza diferentes. No caso do mundo artístico poderemos encontrar diferentes regimes que qualificam e justificam as acções dos actores. Serão estes diferentes regimes uma fonte de tensões e conflitos dentro do mundo artístico, não permitindo a coerência das suas acções e dos princípios que os orientam? Ou, pelo contrário, como são agenciados os diferentes princípios de legitimação para coordenar as acções em torno da construção de um valor de mercado para a obra de arte?

Segundo Nathalie Heinich (1998a), na época contemporânea existe um regime de singularidade que poderá ter a sua origem no regime de inspiração de Boltanski e Thévenot. Este é o regime inimigo dos standards e das equivalências, onde o êxito comercial a curto prazo pode significar a submissão aos cânones vigentes e a incapacidade de criar uma obra original. Simultaneamente, é este regime que possibilita que o valor monetário de uma obra, no campo das artes visuais, possa atingir valores elevados, uma vez que estas obras têm de ver reconhecido um carácter único, inovador e de forte diferenciação artística.

21 A abordagem proposta por Heinich é imposta pela própria natureza do objecto de estudo. Sendo o mundo artístico uma realidade onde se convocam valores de singularidade, de individualidade e de particularidade, é mais difícil para a Sociologia encontrar explicações universais e categorizações gerais. A análise sociológica apenas será possível ao relativizar os sistemas de valor colocados em jogo na avaliação e hierarquização artística, aceitando a sua coexistência e pluralidade a fim de dar lugar à análise de cada um desses sistemas de valores convocados pelos diferentes actores e das suas mediações intersubjectivas.

Se por um lado Heinich enfatiza a questão de quais são os valores intersubjectivos dos actores em jogo na arte contemporânea, e de que forma esses valores orientam as suas acções e representações, conferindo valor artístico, distanciando-se do modelo de Bourdieu, onde é o volume de capitais que posiciona ou hierarquiza o valor artístico, por outro lado, o regime de singularidade de Heinich acaba por admitir também a necessidade da legitimação da avaliação artística. No entanto, aqui esta legitimação acontece através do quadro de valores dos actores envolvidos, sendo que este varia e coexiste na diversidade das situações e contextos a analisar.

No trabalho exploratório desenvolvido na investigação aqui referida, observou-se, através da análise sistemática dos discursos de actores-chave, a convocação de alguns dos princípios de grandeza referidos e presentes enquanto princípios justificativos para orientar as suas acções e representações, e as tensões, conflitos e mediações que surgem da simultaneidade destes diferentes regimes de grandeza.

De modo articulado com a perspectiva de uma sociologia das convenções, é-nos também útil a teoria de Joel Podolny (1993) que aborda o mercado como uma hierarquia de estatutos de produtores. Esta hierarquização de valores e criação de diferentes estatutos, no âmbito do mercado da arte contemporânea, será o resultado de um 
conjunto de interacções coordenadas e assentes em convenções que poderão ser sobre o valor da obra de arte e do artista.

Para finalizar este quadro teórico, identificam-se alguns elementos hipoteticamente determinantes da construção do valor de mercado, assentes nesta teoria sobre a construção do estatuto de mercado e sobre a relação entre o preço e reputação, a trajectória, a afiliação do artista e o capital social ou a redes de relações.

\section{Análise dos discursos}

\section{Dimensões e subdimensões da construção social do valor artístico}

Com o intuito de aprofundar as questões que vêm sido enunciadas optou-se pela aplicação de entrevistas exploratórias a actores-chave do mundo da arte contemporânea. As entrevistas semiestruturadas, efectuadas com baixo grau de directividade a artistas em início de carreira, artistas já estabelecidos no mercado artístico ou artistas consagrados, críticos de arte, curadores e galeristas, constituíram um importante meio de obter novas informações e várias perspectivas ainda não exploradas sobre os temas em questão.

O enquadramento teórico e a observação empírica concretizada através das entrevistas exploratórias tornou possível o desenho de uma grelha de análise que proporcionasse a operacionalização da problemática apresentada. Este processo de vaivém entre a teoria e a observação permitiu a configuração de três dimensões que possibilitam a análise do processo de construção do valor da obra arte e do estatuto de artista, através das entrevistas realizadas.

Estas três dimensões serviram como temas principais para a realização de uma análise de conteúdo temática. Contudo, elas são indissociáveis e contribuem de uma forma inter-relacionada para a construção social do valor artístico na arte contemporânea. Cada uma destas três dimensões foi por sua vez decomposta em duas subdimensões, conforme se apresenta na Tabela 1.

Tabela 1: Resumo da Análise Temática de Conteúdo: Matriz das principais dimensões da Construção do Valor Artístico

\begin{tabular}{|c|c|c|}
\hline & Aquisiçãa & Avaliação \\
\hline $\begin{array}{l}\text { Dimensão } 1 \\
\text { Qualidade } \\
\text { Intrínseca da Obra }\end{array}$ & $\begin{array}{l}\text { - Domínio das técnicas artísticas } \\
\text { - Trabalho árduo, persistente e contínuo } \\
\text { - Actualização e aprofundamento de } \\
\text { conhecimentos } \\
\text { - Singularidade e inovação dentro das tendências } \\
\text { actuais } \\
\text { - Intencionalidade artística - Expressão de } \\
\text { emoções; narrativas associadas }\end{array}$ & $\begin{array}{l}\text { - Disposições dos } \\
\text { especialistas para a } \\
\text { avaliação (habitus) } \\
\text { - Intersubjectividade de } \\
\text { valores } \\
\text { - Posições ocupadas no } \\
\text { campo artístico } \\
\text { - Convenção de valor }\end{array}$ \\
\hline
\end{tabular}




\begin{tabular}{|c|c|c|}
\hline $\begin{array}{l}\text { Dimensão } 2 \\
\text { Notoriedade do } \\
\text { Artista }\end{array}$ & $\begin{array}{l}\text { - Trajectória artística: Participação em concursos; } \\
\text { prémios; número e tipo de exposições realizadas; } \\
\text { internacionalizações } \\
\text { - Reputação das galerias, museus, colecções onde } \\
\text { o artista participa } \\
\text { - Capital Social - redes de relações privilegiadas } \\
\text { - Visibilidade } \\
\text { - Tempo de dedicação e entrega à arte } \\
\text { - Coerência e homogeneidade do percurso } \\
\text { - Imagem de marca } \\
\text { - Inovação e singularidade dentro dos cânones } \\
\text { vigentes }\end{array}$ & $\begin{array}{l}\text { - Valor monetário como } \\
\text { indicador de reputação } \\
\text { - Níveis de consagração } \\
\text { - Consistência de percurso } \\
\text { artístico } \\
\text { - Singularidade }\end{array}$ \\
\hline $\begin{array}{l}\text { Dimensão } 3 \\
\text { Aceitabilidade/ } \\
\text { Receptividade }\end{array}$ & $\begin{array}{l}\text { - Descodificação e interpretação da obra } \\
\text { - Facilidade de compreensão (ex: Figurativo) } \\
\text { - Visibilidade } \\
\text { - Criação de um gosto }\end{array}$ & - Singularidade e distinção \\
\hline
\end{tabular}

\section{Diferentes regimes das economias de valor}

29 Os discursos produzidos pelos entrevistados são um meio privilegiado de darem sentido às suas experiências, uma ocasião de formularem, graças às palavras, os modos pelos quais atribuem significado ao que viveram (Schnapper, 2000: 89). No mundo da arte, tal como noutras áreas da sociedade, a falta de um referente unanimemente reconhecido $\mathrm{e}$ a atomização dos valores fazem com que os entrevistados sintam a necessidade de justificar as suas condutas e as suas opiniões, dispondo de meios intelectuais para elaborar discursos mais ou menos coerentes sobre a sua experiência, com base em sistemas de valores e justificações. Assim, a análise destes discursos constituiu material rico para a interpretação sociológica, à luz da orientação teórica apresentada relativa à abordagem sociológica compreensiva de Luc Boltanski e Laurent Thévenot (1991) e de Nathalie Heinich (1998a). Paralelamente à grelha de análise anterior, considerou-se relevante para esta investigação identificar quais os valores intersubjectivos nos discursos dos actores.

Recorrendo à teorização sobre os regimes que orientam as acções, já explicitados no ponto 2 deste artigo, identificaram-se as referências a cada um destes regimes. Além desta identificação, procurou compreender-se quais são as hierarquizações de valores e as tensões presentes nos discursos e nas práticas dos entrevistados. De que forma é que os valores presentes nas cités dos regimes mercantil, de inspiração, doméstico, de projecto, de opinião, e mais especificamente no regime de singularidade proposto por Heinich se articulam, se combinam ou criam conflitos nas justificações apresentadas pelos actores, ao pronunciarem-se sobre a construção de valor na arte contemporânea. 


\section{Intersubjectividade e coexistência de valores}

31 Uma das questões da presente investigação é a de saber quais os regimes de valores e ordens de grandeza, referidos por Boltanski e Thévenot (1991), invocados pelos actores do mundo artístico nas suas operações críticas e de valorização. Estes valores são utilizados para estabelecer as convenções necessárias, mais ou menos precárias, mais ou menos consensuais, em torno das quais se torna possível coordenar as acções do mundo da arte contemporânea tendo em vista a convenção do valor artístico.

Através da matriz temática, que cruza as diferentes posições estruturais dos actores entrevistados (Galeristas, Jovens em início de carreira, Artistas Consagrados e Críticos de arte) com quatro dos regimes de justificação das economias de grandeza de Boltanski e Thévenot (1991), aos quais acresce o regime de justificação de projecto (Boltanski e Chiapello, 1999) e ainda o regime da singularidade (Heinich, 2004), fez-se um levantamento dos principais regimes evocados ou criticados nos vários discursos analisados. Só assim foi possível começar a vislumbrar algumas das tensões que possam surgir neste mundo da arte contemporânea, em parte devido à coexistência de ordens diferentes de grandeza dos diferentes regimes identificados.

De uma forma imediata, conseguiu distinguir-se nos discursos analisados um recurso frequente ao regime de inspiração. Os actores entrevistados apelam muitas vezes a uma representação do artista criativo, com um dom inato, que deve estar acima das necessidades materiais e que deve manifestar na sua obra, de uma forma espontânea e autêntica, as suas emoções.

Vários excertos mostram uma representação do artista como alguém que se deve submeter a algum sacrifício e privação, que deve renunciar aos bens materiais em prol da sua inspiração, do seu caminho criativo, que tem inquietações, que está longe da racionalidade e perto da subjectividade. Em oposição a esta representação de artista ideal, inspirado, autêntico e humilde é colocada a representação do artista menor, mais racional, que tem uma atitude mais desprendida, mais materialista, e que não leva a actividade artística com total dedicação.

De acordo com o trabalho desenvolvido por Nathalie Heinich (ibidem), a pluralidade de movimentos de tendências artísticas que surgiram na época moderna foram consequência de uma crescente importância de valores como a vocação artística. A profissão de artista surge assente em valores da mesma natureza dos referidos acima, ou seja, assente em valores do regime de inspiração como a vocação, a inspiração, o talento inato, o dom artístico, o espírito de sacrifício e o desprendimento material.

No entanto, para esta autora, com a ruptura do pós-modernismo e com o surgimento da noção de vanguarda durante o século XIX, pouco a pouco esta noção de vocação, de dom inato, foi-se esbatendo, dando origem à valorização da excepção e da originalidade.

37 A progressiva institucionalização da anomia (ausência de regras) começa por se instalar na intenção artística e surge a imposição no mundo artístico da singularidade. Valores como a raridade, a originalidade e a transgressão da norma passam a ser preponderantes na criação artística e a própria noção do que é arte fica abalada. Desta forma, a arte contemporânea remete-nos para um conjunto de valores fundados na singularidade, que passa a ser uma das condições de grandeza neste mundo. 


\section{oposição.}

Tabela 2: Regimes de valores convocados pelos actores entrevistados

\begin{tabular}{|c|c|c|c|c|}
\hline & Arfita Jares & $\begin{array}{l}\text { Artiuas } \\
\text { Castagradas }\end{array}$ & Galeriatas & Critesen \\
\hline Mercasta & $x \bullet$ & $x \in$ & $x \bullet$ & \\
\hline Sinadaritade & $\bullet$ & $\bullet$ & $\bullet$ & - \\
\hline Iosoiracto & $\bullet$ & $\bullet$ & $\bullet$ & $\bullet$ \\
\hline Projecto & - & & - & \\
\hline Domessico & & - & & \\
\hline Opinialo & & & $\bullet$ & - \\
\hline
\end{tabular}

Valores convocados por oposição

Valores convocados por adesão

\section{Principais conclusões}

Após uma análise de conteúdo exaustiva às entrevistas realizadas surgiram, entre outras, duas novas questões de elevada pertinência no âmbito da investigação: A articulação entre as posições ocupadas pelos diferentes actores no campo artístico, e as representações e os regimes de valores por eles evocados e a hipótese de existirem dois regimes ou estratégias de mercado diferentes, que poderão ser articulados entre si, identificados pelos próprios entrevistados, e que comportam mecanismos e dinâmicas diferentes, no que diz respeito à aquisição de notoriedade.

Contudo, algumas conclusões resultaram desta análise. Partindo da questão inicial sobre o valor da arte contemporânea, conclui-se que é um valor difícil de determinar. 0 valor monetário parece não ser uma boa medida do valor artístico na época contemporânea, pois uma obra vendida por uma pequena quantia posteriormente poderá atingir valores elevados se chegar, por exemplo, a um leilão, onde habitualmente são atingidos os valores mais elevados. Quando uma obra surge pela primeira vez no mercado é inevitável que lhe seja atribuído um valor. A partir do momento que lhe é associado um nome reconhecido no meio artístico, imediatamente o seu valor aumenta.

Uma das discussões da presente investigação sobre a obra contemporânea é a de compreender quais são os critérios e a forma como lhe é conferido um valor monetário e simbólico. No entanto, a arte contemporânea apresenta características de novidade e de singularidade que saem das referências de avaliação da arte clássica. A novidade da arte contemporânea não permite criar critérios objectiváveis de qualidade de uma obra. 
43 A partir da época contemporânea, com o aparecimento da arte conceptual, vanguardista e de outros movimentos contemporâneos, o valor da arte passou a estar relacionado com o regime, o que Nathalie Heinich (1998a) designa de singularidade. Neste regime os standards e as equivalências não são bem vistos, o êxito comercial a curto prazo arrisca-se a significar apenas submissão à especulação, a cânones dominantes e à incapacidade de criar algo de original. Contudo, esta originalidade e transgressão das normas que se esperam de um artista contemporâneo, para que tenha algum valor, comporta um elevado grau de incerteza. Por um lado, se não há equivalências nem referência a padrões de equivalência, o valor conferido é difícil de estabelecer; por outro lado, o próprio artista arrisca-se a sair do jogo e cair no eterno anonimato. Perante tal incerteza, quais são então os mecanismos que permitem estabelecer critérios de qualidade na arte contemporânea?

o trabalho exploratório desenvolvido indica que o valor é atribuído com base na percepção de qualidade e na hierarquização de reputações. A qualidade intrínseca da obra, avaliada e legitimada pelos especialistas, é imprescindível. No entanto, os critérios para esta avaliação acabam por não ser muito objectivos, e os que o são (como por exemplo o domínio das técnicas) não são os mais preponderantes para o valor da obra. É a construção de uma reputação assente em atributos como: a trajectória do artista, o capital social adquirido, a visibilidade, a dedicação, a consistência e imagem de marca artística, bem como a singularidade dentro de alguns limites, que permitem ao artista adquirir notoriedade e conferir valor às suas criações. Além da reputação e da notoriedade, será necessário também que a obra seja aceite, isto é, seja interpretada, descodificada e integrada no mundo da arte contemporânea. Este será o papel fundamental dos mediadores entre a produção e a recepção da arte, como o são os críticos, os galeristas, os directores de museus, entre outros agentes.

Um outro aspecto a salientar que aparenta ser importante na construção de notoriedades é a influência recíproca que as reputações têm entre si. Verifica-se em vários pontos da análise que a reputação de um artista é influenciada pela reputação dos actores e instituições com que interage, e por sua vez a sua própria reputação irá também contribuir para a construção das reputações dos mesmos actores e instituições.

Uma das hipóteses de trabalho identificadas no decorrer desta investigação e que poderá vir a ser verificada num projecto futuro é a de que o valor artístico depende da reputação do artista e da posição que este ocupa na hierarquia das notoriedades artísticas.

47 Outra questão que parece relevante salientar como sendo produto desta investigação é a de que este valor atribuído a um artista ou uma obra tem de ser o produto de uma convenção ou de um acordo entre vários actores que participam na construção deste valor. Cada um destes actores tem um olhar diferente sobre uma determinada obra de arte. Este olhar depende da posição que ocupam no campo artístico, depende das suas disposições ou habitus, e depende das suas estruturas mentais e dos conjuntos de valores que convocam para avaliar e criticar a arte contemporânea. Para a compreensão de um meio polémico e conflituoso como este, será necessário relativizar as avaliações que são feitas. Vários sistemas de valores são convocados pelos actores participantes da construção de valor, para argumentar e justificar as suas acções e representações. Os actores poderão sentir algumas tensões entre as suas práticas e representações, em virtude de as suas práticas nem sempre estarem de acordo com os princípios aceites e legítimos no mundo da arte. Refere-se aqui o exemplo das práticas 
comerciais dos galeristas, que evocam valores de um mundo mercantil e que não são compatíveis com os valores de grandeza maior no mundo artístico, que por sua vez convoca valores de inspiração e singularidade. No entanto, com a justificação destas práticas mercantis através de outros valores mais compatíveis com as grandezas da arte, os actores podem encontrar justificação para as suas práticas através de discursos mais consensuais, como é o caso do regime de projecto, por exemplo. Apesar de toda esta diversidade de valores, de práticas e de olhares é possível chegar-se a uma convenção do valor artístico. $O$ valor monetário é o exemplo de uma dessas convenções que é estabelecida em grande parte pela reputação do artista. A hipótese que se oferece aqui é a de que o valor monetário seja um indicador da posição que o artista ocupa na hierarquia das reputações. Salvo situações de especulação - aparentemente mal vistas por abalarem a própria confiança na perenidade das reputações -, quanto mais elevada é a reputação de um artista, mais elevado é o valor monetário atribuído aos seus trabalhos.

Para que uma obra adquira valor artístico, ou para que o artista seja considerado como tal, não basta que este se auto-intitule artista contemporâneo e afirme que as suas criações são arte. $O$ trabalho do artista é fazer com que haja uma articulação dos vários actores em torno do seu trabalho que o classifique como arte contemporânea. É necessário que haja uma convenção, entre os diferentes actores intervenientes no processo de construção de valor artístico, de que uma determinada produção tem valor. Esta convenção permite que a obra e o artista adquiram estatuto de mercado e este processo de legitimação só acontece através da cooperação dos diversos actores para um fim comum.

Perante a diversidade de critérios, de olhares, de disposições e de princípios orientadores das acções dos diversos actores, como é que se torna possível esta convenção? De que forma é que os actores encontram explicações universais e categorizações gerais para a arte contemporânea?

Dentro de uma perspectiva da sociologia compreensiva, considera-se que a abordagem mais interessante para esta questão é a da relativização das situações, tentando identificar em cada uma delas quais são os princípios comuns convocados pelos actores para justificar as suas acções e engrandecer as suas avaliações. A sociologia aqui não pode generalizar e categorizar de uma forma universal, mas terá de relativizar os sistemas de valor colocados em jogo na avaliação artística, apontando a sua coexistência e pluralidade ${ }^{1}$. Neste caso da arte contemporânea, a interioridade ${ }^{2}$ do artista e a originalidade da obra são aspectos susceptíveis de constituir argumentos de um sistema de valores como o do regime de singularidade, e que são válidos aos olhos dos especialistas e do público.

51 De acordo com trabalho teórico da presente investigação e com a análise das entrevistas exploratórias, um destes princípios comuns evocados pelos diferentes actores é a grandeza da singularidade. Os valores presentes na avaliação da obra, da notoriedade do artista e da aceitação da obra são do mundo da singularidade. É aquilo que a obra e o artista têm de especial, de original e de único para marcar a diferença, que em parte lhes confere o estatuto necessário para entrar no mercado artístico. É através do reconhecimento de singularidade que o artista adquire notoriedade e reputação e é através da sua reputação que adquire uma posição no mercado artístico.

52 Decorrente dos discursos dos entrevistados surge ainda uma outra hipótese, que é a de o mercado artístico apresentar diferentes estratégias de aquisição de estatuto de 
mercado, que podem ser duas formas de articulação entre o regime de mercado e dois outros regimes: o da singularidade/inspiração e o da reputação.

Relativamente aos passos para a consagração ou, mais concretamente, às dinâmicas de aquisição de notoriedade, as entrevistas sugeriram dois processos diferentes, ou formas distintas de articulação de regimes de justificação. De acordo com a percepção e os valores convocados pelos entrevistados, pode identificar-se um regime de mercado em que o discurso sobre a percepção de qualidade assenta numa trajectória do artista coerente que vai amadurecendo com um percurso longo e de sacrifício, cujo culminar é a consagração, constituindo um valor de mercado seguro. Simultaneamente a este regime de mercado, poderá articular-se outro, cuja dinâmica é criticada por alguns dos actores (consoante a posição que ocupam), e que se caracteriza por uma mais recente geração de artistas, que procuram visibilidade e notoriedade de uma forma mais rápida, assente em estratégias de marketing e de autopromoção, que permitem a consagração, que pode ser efémera e considerada especulativa pelos mais "conservadores". Esta análise da distinção de estratégias de mercado e diferentes articulações de justificações, leva-nos a uma reflexão sobre o quadro de valores que orientam as acções dos actores nos diferentes contextos e posições do campo artístico, e que poderão contribuir para uma profissionalização do estatuto de artista.

Estas questões, a par de outras que foram sendo identificadas de uma forma metódica e sustentada pela teoria e pela observação, poderão ser desenvolvidas num próximo projecto de investigação em que seja possível uma maior sustentação empírica das questões levantadas. Considera-se, no entanto, que todo o trabalho exploratório a que o presente artigo se refere constitui uma fundamentação e uma base consistente para que se possa progredir para outro trabalho de investigação.

\section{BIBLIOGRAFIA}

BECKER, H. S. (1982), Art World, Berkeley, University of California Press.

BECKER, H. S. (1994), "Distributing Art Works”, in A. Melo (org.), Arte e Dinheiro, Lisboa, Assírio \& Alvim.

BOLTANSKI, L. (2001), “A Moral da Rede? Críticas e justificações nas recentes evoluções do capitalismo”, Forum Sociológico, 5/6 (2.. Série), Lisboa, IEDS, UNL, p. 14.

BOLTANSKI, L. e L. Thévenot (1991), De La Justification - Les Économies de la Grandeur, Paris, Gallimard.

BOLTANSKI, L. e È. Chiapello (1999), Le Nouvel Esprit du Capitalism, Paris, Gallimard.

BORGES, V. (2002), “Artistas em rede ou artistas sem rede: Reflexões sobre o teatro em Portugal”, Sociologia, Problemas e Práticas, 40, pp. 86-106.

BOURDIEU, P. (1989), O Poder Simbólico, Lisboa, Difel, p. 292.

BOURDIEU, P. (2005), A Economia das Trocas Simbólicas, São Paulo, Editora Perspectiva. 
CONDE, I. (1994), “Obra e Valor. A questão da relevância” in A. Melo (org.), Arte e Dinheiro, Lisboa, Assírio \& Alvim.

GHIGLIONE, R. e B. Matalon (1992), o Inquérito - Teoria e Prática, Oeiras, Celta Editora.

GRANOVETTER, M. ([1985] 2003), “Acção Económica e Estrutura Social: O problema da incrustação”, in J. Peixoto e R. Marques (org.), A Nova Sociologia Económica, Oeiras, Celta, pp. 69-102.

HEINICH, N. (1998a), Le triple jeu de l'art contemporain, Paris, Les Éditions Minuit.

HEINICH, N. (1998b), Ce que l'art fait à la sociologie, Paris, Les Éditions Minuit.

HEINICH, N. (2004), La sociologie de l'art, Paris, Éditions La Découverte.

LÉVESQUE, Benoît et al. (2001), La Nouvelle Sociologie Économique - Originalité et diversité des approches, Paris, Ed. Desclée de Brouwe, pp. 103-121.

MOULIN, R. (1967), L'Artiste, l'institution et le marché, Paris, Flammarion.

MOULIN, R. (1995), De la Valeur de l'Art, Paris, Flammarion.

PODOLNY, J. F. (1993), “A Status-based model of market competition”, American Journal of Sociology, 98 (4), pp. 829-872.

SCHNAPPER, D. (2000), A Compreensão Sociológica, Lisboa, Gradiva.

SCHÖNFELD, S. e A. Reinstaller (2005), The effects of art gallery and artist reputation on prices in primary market for art: a note, Vienna, University of Economics, 90, pp. 1-11.

VELTHUIS, O. (2005), Talking Prices: Symbolic Meanings of Prices on the Market for Contemporary Art, New Jersey, Princeton University Press.

\section{NOTAS}

1. Cf. N. Heinich (1998b), Ce que l'art fait à la sociologie.

2. Entende-se aqui por interioridade os aspectos relacionados com a intenção e com a expressão emocional do artista.

\section{RESUMOS}

Qualquer valor de mercado resulta de uma construção social. Por maioria de razão, esse é o caso do valor de uma obra de arte: uma vez que a percepção de qualidade do objecto, enquanto determinante do seu valor de uso, não é imediatamente objectivável através de propriedades tangíveis, é necessário que um conjunto significativo de actores sociais certifiquem e atribuam valor à obra. Através da análise exploratória dos discursos de várias categorias de actores envolvidos, das posições por estes ocupadas e dos valores orientadores das suas acções neste processo, é possível apreender que atributos são necessários para que uma obra ou um artista adquiram estatuto de mercado e lhes seja atribuído um determinado valor, e por que processos esses atributos são construídos. Abordando o mercado como uma hierarquia de valores e de 
estatutos de produtores, enfatiza-se a compreensão dos valores intersubjectivos invocados pelos actores em jogo na arte contemporânea, e de que forma estes valores orientam as suas acções e representações.

All market values result from a social construction. This all the more so with the value of a work of art: since the perception of the object's quality, as a determinant of its use-value, cannot be immediately objectified by tangible properties, it is required that a significant set of social authors certify and confer a value to the art work. Through a comprehensive sociological approach which takes the market as a hierarchy of values and of producers' statuses, this research analyses several categories of involved actors and their speeches, the positions they hold and the values guiding their actions throughout this process. We can ascertain which attributes are needed for an artwork or an artist to acquire market status and for a certain value to be bestowed on them, and which processes construct such attributes.

\section{ÍNDICE}

Keywords: contemporary art, artist, market status, value

Palavras-chave: arte contemporânea, artista, estatuto de mercado, valor

\section{AUTOR}

\section{FILIPA ALMEIDA}

Mestre em Sociologia Económica pela Faculdade de Ciências Sociais e Humanas da Universidade Nova de Lisboa filipa_baumberg@yahoo.com 